\title{
Pig Social Status and Chronic Cold or Crowd Stressors Differentially Impacted Immune Response
}

\author{
Janeen L. Salak-Johnson ${ }^{1 *}$, Sherrie R. Webb ${ }^{2}$ \\ ${ }^{1}$ Department of Animal \& Food Sciences, Oklahoma State University, Stillwater, OK, USA \\ ${ }^{2}$ Department of Animal Sciences, University of Illinois, Urbana, IL, USA \\ Email: *janeen.johnson@okstate.edu
}

How to cite this paper: Salak-Johnson, J.L. and Webb, S.R. (2018) Pig Social Status and Chronic Cold or Crowd Stressors Differentially Impacted Immune Response. Open Journal of Animal Sciences, 8, 280-293. https://doi.org/10.4236/ojas.2018.83021

Received: June 1, 2018

Accepted: July 10, 2018

Published: July 13, 2018

Copyright $\odot 2018$ by authors and Scientific Research Publishing Inc. This work is licensed under the Creative Commons Attribution International License (CC BY 4.0).

http://creativecommons.org/licenses/by/4.0/

\section{(c) (i) Open Access}

\begin{abstract}
The objectives of this study were to determine the effects of 4-day of cold and crowding stressors and social status on pig immune responsiveness to these stressors. Three unfamiliar white crossbred female pigs were mixed and assigned to ambient temperatures of either $8^{\circ} \mathrm{C}(\mathrm{COLD})$ or $22^{\circ} \mathrm{C}$ (control; TN) and floor-space of either $0.26 \mathrm{~m}^{2} / \mathrm{pig}$ (reduced, CROWD) or $0.45 \mathrm{~m}^{2} / \mathrm{pig}$ (adequate, CONT) over six blocks $(\mathrm{n}=72)$. Pigs were identified as dominant (DOM), intermediate (INT), or submissive (SUB) based on aggressive encounters that occurred during the first 24 -h post-mixing. There were no interactive effects of temperature $\times$ floor-space on immune indices. There was social status $\times$ stressor for body weight, natural killer (NK) cell cytotoxicity and phagocytosis $(P<0.05)$. DOM pigs that were COLD or CROWD gained the least amount of body weight compared to either INT or SUB pigs $(P<$ 0.01). INT and SUB pigs subjected to CROWD stress gained more weight compared to their counterparts subjected to COLD temperature or CONT floor-space $(P<0.05)$. NK cytotoxicity was greater among CROWD-INT pigs and phagocytosis was greater among COLD- and CROWD-SUB pigs. Also, INT pigs had lower $\mathrm{T}$ and $\mathrm{B}$ cell proliferation regardless of the stressor. COLD stress significantly reduced NK cytotoxicity, total Immunoglobulin-G, and B-cell proliferation and enhanced total WBC counts and T-cell proliferation. These data imply that various immune indices were either enhanced or suppressed by COLD stress, but concurrent exposure to CROWD stressor did not exacerbate these effects. Moreover, social status played a role in determining a pig's immune responsiveness as it modulated differential homeostatic stress response as the pig attempted to cope with stress.
\end{abstract}

\section{Keywords}

Cold, Immune, Pigs, Social Status, Stress 


\section{Introduction}

In commercial agriculture, pigs are frequently exposed to stressors such as weaning, heat, cold, commingling, and crowding, each of which can be perceived by pigs as a threat to their homeostasis, thus negatively impacting well-being. These relatively common stressors have been shown to alter lymphocyte proliferation, humoral immune responses, and natural killer cell (NK) cytotoxicity [1] [2] [3] [4] and affect disease susceptibility [5] [6]. However, not all stressors affect the immune system or cause disease, which is partly explained by the type (physical vs. psychological) and duration (acute vs. chronic) of the stressor, the aspect of the immune system being measured, and more importantly pig social status [6] [7]. Animals most affected by a stressor due to its' social status is more likely to display stress-related pathologies [8]. Understanding the effects of the production environment of the pigs on their immune system may allow the industry to better manage some of the stressors that negatively impact health and productivity.

Mixing of unfamiliar pigs is a common practice that results in aggressive encounters between pigs to establish social hierarchy [9] [10]. In a stressful situation, social status can often influence the biological response and consequences more than the stressor alone [3] [4] [11]. It is possible that social status may dictate homeostatic mechanisms initiated in response to a specific stimulus. Consequences of acute and chronic stress on immune responsiveness in pigs are highly variable. Moreover, data are limited on the effects of concurrent stressors even though it is common in modern pig production for pigs to be confronted by multiple concurrent stressors. Therefore, we designed a study to determine the consequences of multiple concurrent stressors on animal health, performance, and well-being. Our objectives were to determine the effects of simultaneously imposing acute-regrouping in conjunction with 4-day of cold and crowding stressors on various aspects of innate immunity and the impact of pig social status on the immune responsiveness to these stressors.

\section{Materials and Methods}

\subsection{Animals and Experimental Design}

The University of Illinois Institutional Animal Care and Use Committee approved all animal procedures used in this study. Six-week-old female Landrace $x$ Yorkshire crossbred pigs $(n=72)$ from the University of Illinois Swine Research Center were assigned to a $2 \times 2$ factorial experiment. Prior to the start of the experiment, four female littermates were housed in pens with adequate floor-space allowance $\left(0.45 \mathrm{~m}^{2} / \mathrm{pig}\right)$ within an environmentally-controlled chamber with an ambient temperature of $22^{\circ} \mathrm{C} \pm 1{ }^{\circ} \mathrm{C}$ and illumination followed a $12 \mathrm{~h}$ of light and $12 \mathrm{~h}$ of dark (lights on at 6:00 am and lights off at 6:00 pm). During the one-week acclimation period, pigs had ad libitum access to water and a diet formulated to meet or exceed recommended nutrient allowances for young pigs 
(NRC, 2001). After the adjustment period, one pig from each litter, matched for BW was assigned to a temperature stressor of either: $22^{\circ} \mathrm{C}$ (control; TN) or $8^{\circ} \mathrm{C}$ (COLD) and to a floor-space stressor of either: $0.45 \mathrm{~m}^{2} /$ pig (control; CONT) or $0.26 \mathrm{~m}^{2} /$ pig (reduced; CROWD) for 4 continuous days. During the experimental period, all pigs were fed a fixed amount of feed, based on their voluntary feed intake during the one-week adjustment. Pigs were meal-fed because preliminary findings revealed that cold-stressed pigs increased feed intake to cope with the stressor.

\subsection{Cell Counts, Differentials, and Cell Isolation}

All pigs were held in a supine position for blood collection on days 0,1 , and 4 post-treatments. Approximately $12 \mathrm{~mL}$ of blood was collected via jugular vein-puncture using syringes containing either sodium heparin or EDTA (procedure last $<2 \mathrm{~min}$ ). Total white blood cell (WBC) counts were calculated electronically using a Coulter Z1 particle counter (Beckman Coulter, Indianapolis, IN) by adding $10 \mu \mathrm{L}$ of whole blood to $10 \mathrm{~mL}$ of Isoflow (Beckman Coulter), and red blood cells were lysed with Zap-oglobin (Beckman Coulter). Whole-blood smears were made, fixed in methanol, stained with Hema 3 staining solutions (Fisher Scientific, Houston, TX), and viewed under a light microscope to determine leukocyte differential by counting 100 cells per slide.

For functional immune assays, whole blood was diluted with Roswell Park Memorial Institute medium (RPMI; Gibco, Carlsbad, CA) layered over Histopaque 1077 (density = $1.077 \mathrm{~g} / \mathrm{mL}$; Sigma, Saint Louis, MO) and 1119 (density = $1.119 \mathrm{~g} / \mathrm{mL}$; Sigma Aldrich) and centrifuged at $700 \mathrm{~g}$ for $30 \mathrm{~min}$ at $25^{\circ} \mathrm{C}$. Lymphocytes were removed from the 1077 layer and neutrophils were removed from the 1119 layer. Once neutrophils were removed from the 1119 layer, the red blood cells were lysed. Isolated lymphocytes and neutrophils cell populations were washed twice in RPMI, resuspended, counted, and cell concentrations were adjusted with RPMI based on assay cell requirements.

\subsection{Immune Assays}

A mitogen-induced lymphocyte proliferation assay was performed using a nonradioactive cell proliferation assay (CellTiter $96^{\circledR}$; Promega, Madison, WI) as described previously [12]. Briefly, lymphocytes were adjusted to cell concentration $5 \times 10^{6}$ cells/ml in RPMI-FBS (Sigma). Mitogens, concanavalin-A (Con-A) and lipopolysaccharide (LPS; Sigma), were added in triplicate at 0, 25, and 50 $\mu \mathrm{g} / \mathrm{ml}$ and plates were incubated for $48-\mathrm{h}$ at $37^{\circ} \mathrm{C}$. Dye solution was added and plates were incubated for 4 -h. Stop solution $(100 \mu \mathrm{L})$ was added and plates incubated overnight at $37^{\circ} \mathrm{C}$, then read with a microplate reader (BIO-TEK Instruments) at wavelength $550 \mathrm{~nm}$ and reference wavelength $690 \mathrm{~nm}$. Results are expressed as a proliferation index (PI):

PI = optical density of stimulated cells $\div$ optical density of non-stimulated cells

Natural killer (NK) cytotoxicity was measured using a commercially available 
nonradioactive cytotoxicity detection kit (Roche Diagnostics, Indianapolis, IN) in conjunction with a radioactive NK assay protocol as described [13]. Lymphocytes were adjusted to $1 \times 10^{7}$ cells/ml in RPMI-FBS, and K-562 chronic human myelogenous leukemia cells (American Tissue Type Culture Collection, Manassas, VA) were adjusted to 10,000 cells per well. Samples were run in triplicate at effector (lymphocytes)-to-target cell (K-562) ratios (E: T) of 12.5, 25, 50, and 100:1, respectively. Plates were read using a microplate reader (BIO-TEK Instruments) at wavelength $490 \mathrm{~nm}$ with reference wavelength $690 \mathrm{~nm}$. The assay was considered valid if maximum release divided by spontaneous release was $\leq 20 \%$. Percentage cytotoxicity was calculated using the formula:

Cytotoxicity $(\%)=\left(\right.$ optical density experimental values - optical density $\left._{\text {spontaneous release }}\right) \div$ (optical density $y_{\text {maximum release }}-$ optical density spontaneous release $_{\text {e }}$ ).

\subsection{Plasma Immunoglobulin-G}

Total immunoglobulin G (IgG) was performed as described [2] with minor modifications. Plasma samples were diluted 1:3000 in 0.05\% Tween-PBS and run in duplicate on a 96-well microtiter plate coated with porcine IgG (Jackson Immunoresearch, West Grove, PA). Rabbit anti-pig IgG (Sigma, St. Louis, MO) was added, plates incubated $2 \mathrm{~h}$ at room temperature, then washed three times with $0.05 \%$ Tween-PBS. Enzyme-linked anti-rabbit IgG (1:7500; Jackson Immunoresearch) was added, plates incubated $1 \mathrm{~h}$, then washed three times. Substrate solution ( $1 \mathrm{mg} / \mathrm{ml}$, P-nitrophenyl phosphate; Sigma) was added and plates were incubated 30-min. Reaction was stopped with $100 \mu \mathrm{L} 2 \mathrm{M} \mathrm{NaOH}$. Plates were read using a microplate reader (BIO-TEK Instruments, Winooski, VT) at wavelength $405 \mathrm{~nm}$. A standard curve was used to determine total IgG concentration in unknown samples.

\subsection{Cortisol, Prolactin, and Cytokines}

Cortisol concentrations were determined at days 0,1 and 4 post-treatments, using Coat-A-Count assay kit, following manufacturer's protocol (Diagnostic Products, Los Angeles, CA). Samples were analyzed in duplicate. Minimal detectable concentration of the assay was $2 \mathrm{ng} / \mathrm{ml}$ with mean intra- and inter-assay coefficients of variation were $7.0 \%$ and $14.5 \%$, respectively.

Prolactin concentrations were measured by RIA using a specific anti-porcine prolactin antibody in a modification of the assay described previously [14]. Primary antibody (pPRL AFP-0842255Rb; NHPP and NIDDK, Torrance, CA) was diluted to 1:50,000 in working solution and a final tube dilution of 1:200,000. Porcine serum depressed binding in parallel to the standard curve in the PRL assay. Mean intra- and inter-assay coefficients of variation were $8.5 \%$ and $16.4 \%$ respectively, and assay sensitivity averaged $0.54 \mathrm{ng} / \mathrm{ml}$.

Interferon and Interleukin-10 and -12 were measured using commercially available ELSIA kits for each cytokine (Quantikine, R \& D Systems, Minneapolis, $\mathrm{MN}$ ). Analyses were conducted as outlined by the manufacturer. 


\subsection{Behavior}

All pigs within the pen were uniquely marked with a livestock marking crayon. To determine social status, pigs were video-recorded for 24-h post-mixing and aggressive interactions were registered from video-records (30 frames/s). Aggressive and submissive behaviors were identified based on previously described ethogram [10]. Pigs were identified as dominant (DOM), intermediate (INT), or submissive (SUB) based on the outcome of each agnostic encounter. Essentially, DOM pigs won all agnostic encounters in which they were engaged, whereas INT pigs lost one or more fights to the DOM pig. A SUB pig was identified based primarily on submissive postures and behaviors (i.e., avoidance) toward other pigs in the pen.

\subsection{Statistical Analysis}

All traits were tested for departures from normal distribution using Shapiro-Wilk test. Data lacking normality were transformed logarithmically using $\log _{10}$. A linear mixed model was used to analyze all variables using MIXED procedure of SAS (SAS Inst., Cary, NC). The main effects for fixed variables temperature, floor-space, social status, and all interactions with repeated structure of day. Random effects of chamber and replicate were included in the model. Logarithmic transformation P-values are presented for all variables except total WBC, differentials, cell counts, NK cytotoxicity, and body weight. Means presented are non-transformed means for those variables that required logarithmic transformation.

\section{Results}

No interactive effects of temperature $\times$ floor-space stressors occurred for any immune, endocrine, or body weight measures. There were significant interactive effects of pig social status $\times$ stressors for pig body weight (Figure 1), NK cytotoxicity (Figure 2), and phagocytosis (Figure 3). Over the 4-d experimental period, DOM pigs subjected to either COLD or CROWD stressors gained the least amount of body weight compared to socially INT or SUB pigs $(P<0.05$; Figure 1). Socially, INT pigs that were CROWD-stressed gained the most body weight compared to DOM and SUB pigs as well as their CONT floor-space counterparts $(P<0.01)$.

Socially, DOM and SUB pigs subjected to CONT floor-space and TN temperature had greater $(P<0.05)$ NK cytotoxicity compared to INT pigs (Figure 2$)$; whereas, INT pigs at TN temperature and CROWD stressor had greater $(P<$ $0.01)$ NK cytotoxicity than either DOM or SUB pigs (Figure 2). Socially, SUB pigs subjected to CROWD and COLD stressors had greater $(P<0.01)$ phagocytosis when compared to either DOM or SUB pigs (Figure 3). Overall, within in social status, NK cytotoxicity was greatest among INT pigs subjected to CROWD stressor and TN temperature compared to their counterparts that were COLD and CROWD stressed $(P<0.005$, Figure 2$)$. Phagocytosis was greatest 


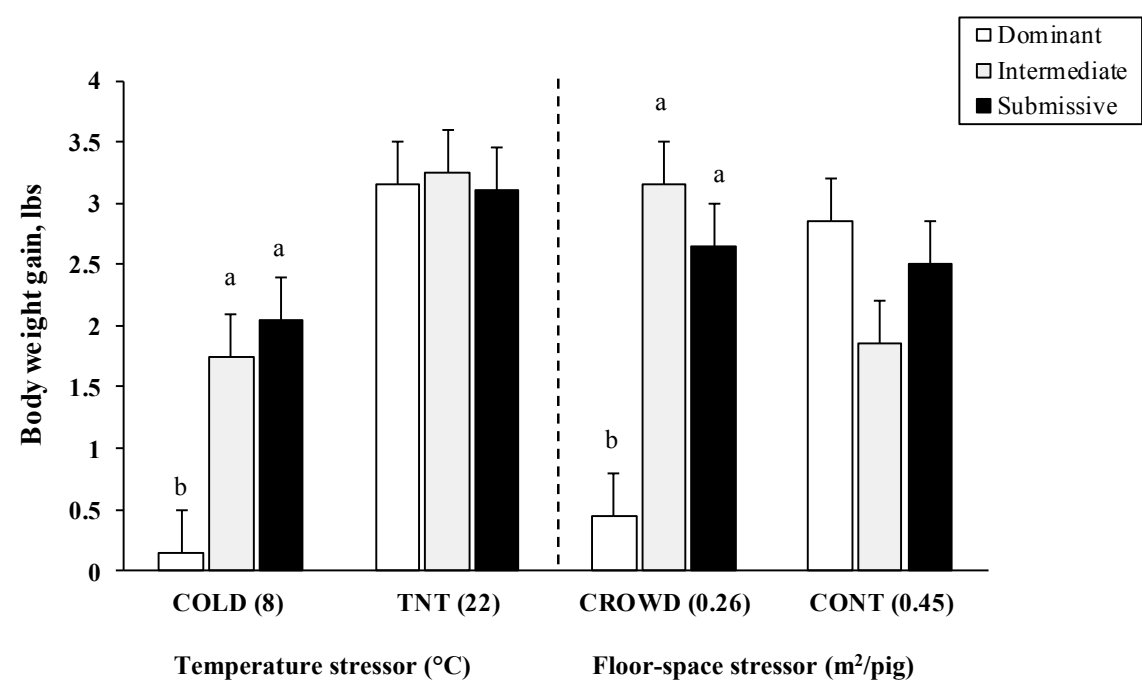

Figure 1. Example of a figure caption (figure caption). Effect of pig social status and cold $\left(8^{\circ} \mathrm{C}\right)$ or crowd stressors $\left(0.26 \mathrm{~m}^{2} / \mathrm{pig}\right)$ on body weight gain (lbs) at day 4 post-stress. Socially, dominant pigs exposed to cold or crowd stressors gained less body weight than either intermediate or submissive pigs $(P<0.05)$. Data are expressed as Least square means \pm SE within treatment. A different letter $(\mathrm{a}, \mathrm{b})$ differ at $P \leq 0.05$.

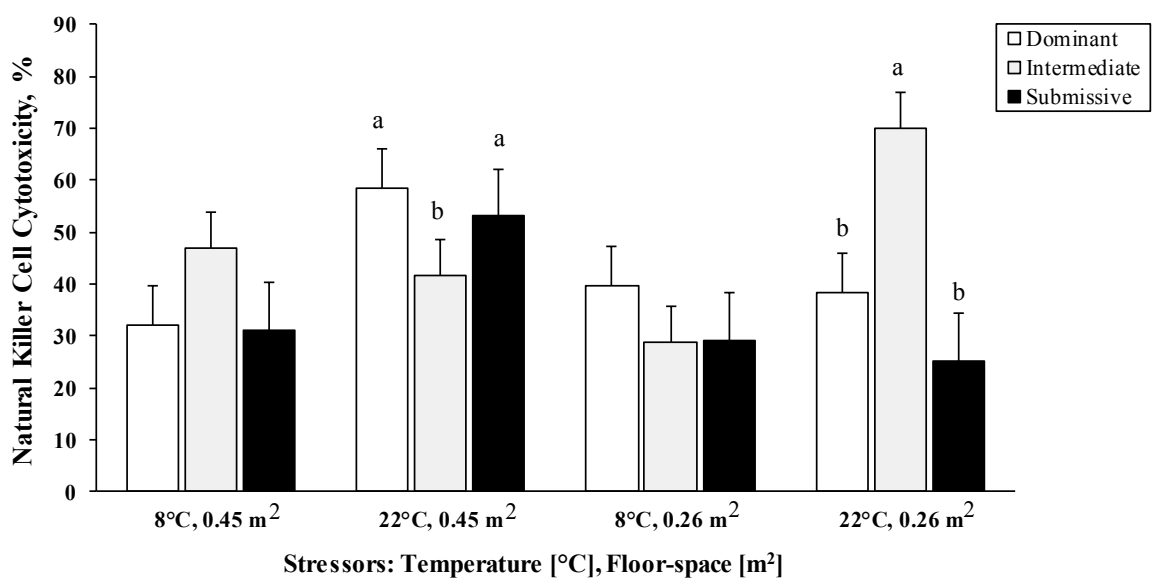

Figure 2. Interactive effect of pig social status by stressor for natural killer (NK) cell cytotoxicity. Socially, dominant and submissive pigs had enhanced NK cell cytotoxicity at thermonuetral ambient temperature $\left(22^{\circ} \mathrm{C}\right)$ and adequate floor-space $\left(0.45 \mathrm{~m}^{2} / \mathrm{pig}\right)$, whereas socially intermediate pigs had enhanced NK cytotoxicity at ambient cold temperature $\left(8^{\circ} \mathrm{C}\right)$ and reduced floor-space $\left(0.26 \mathrm{~m}^{2} / \mathrm{pig}\right)$. Least square means \pm SE within treatment between social status with a different letter $(\mathrm{a}, \mathrm{b})$ differ at $P \leq 0.05$.

for SUB pigs subjected to COLD and CROWD stressors and compared to their counterparts subjected to CROWD stressors and TN temperature $(P<0.05$; Figure 3).

There was an interactive effect of temperature $\times$ day for total WBC counts $(P$ $<0.001$; Figure 4(a)) and total plasma IgG $(P=0.01$; Figure $4(\mathrm{~b}))$. At d 4 , total WBC counts were greater for COLD-pigs compared to pigs at ambient TN temperature. Plasma IgG was less at $\mathrm{d} 1$ and 4 for COLD-pigs compared to pigs at ambient $\mathrm{TN}$ temperature. 


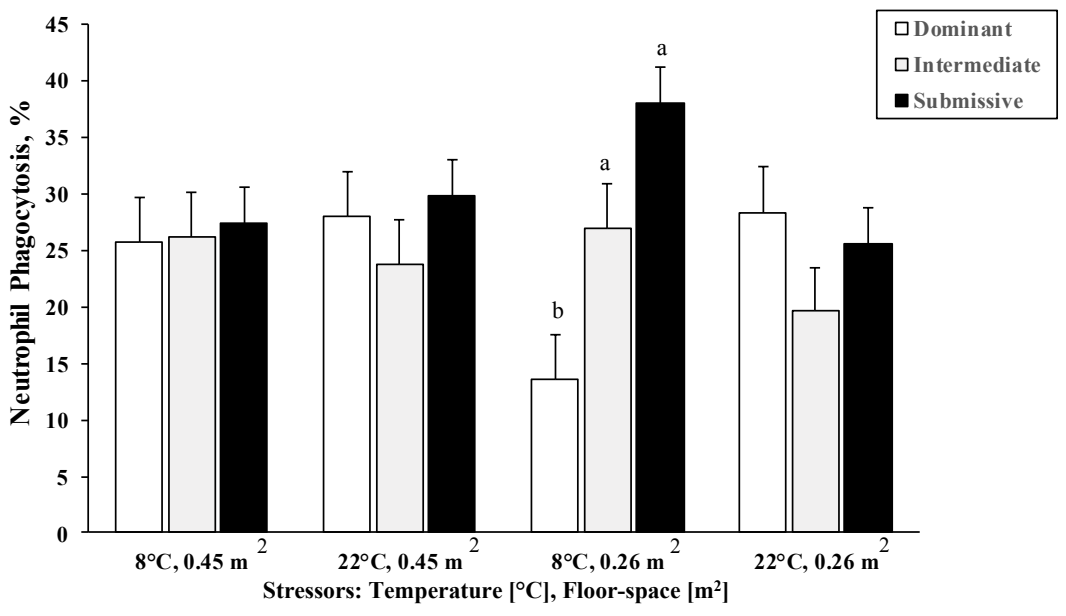

Figure 3. Interactive effect of pig social status by stressor for phagocytosis. Socially, intermediate and submissive pigs had enhanced phagocytosis at ambient cold temperature $\left(8^{\circ} \mathrm{C}\right)$ and reduced floor-space $\left(0.26 \mathrm{~m}^{2} / \mathrm{pig}\right)$ compared to dominant pigs. Least square means \pm SE within treatment between social status with a different letter $(\mathrm{a}, \mathrm{b}) \operatorname{differ}$ at $P$ $\leq 0.05$.

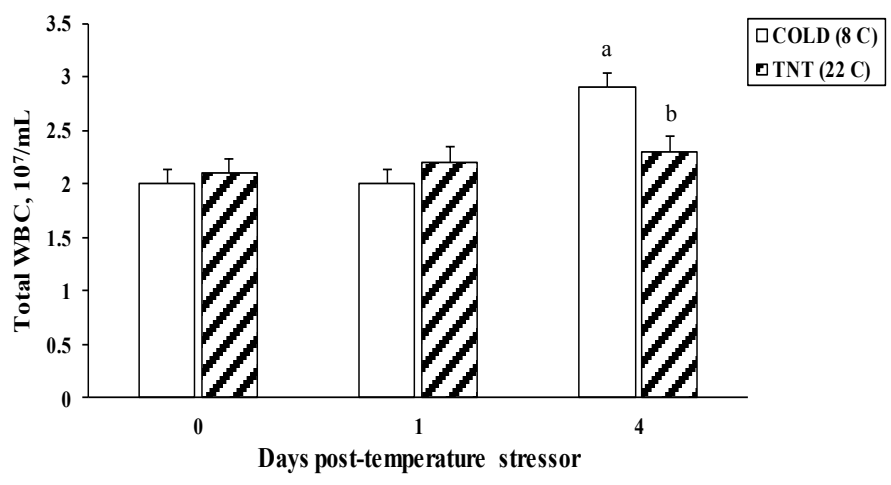

(a)

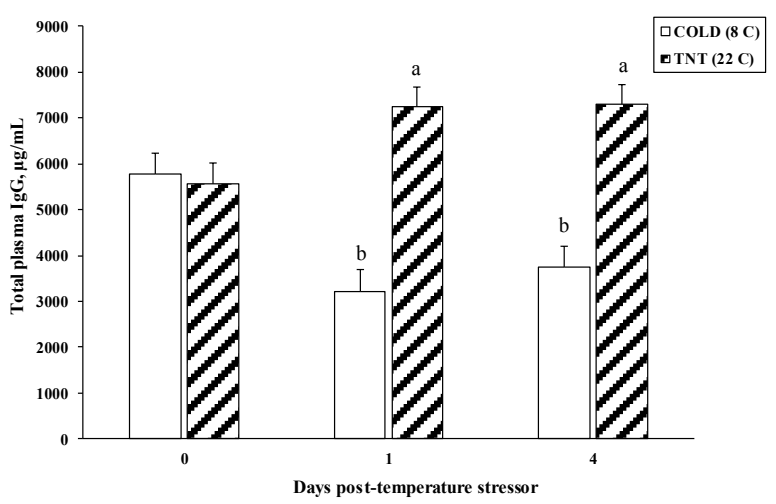

(b)

Figure 4. Interactive effect of day by cold stressor for (a) total white blood cell (WBC) counts and (b) total plasma immunoglobulin-G (IgG). After 4-days of cold-stress (a) total WBC were greater for cold-stress $\left(8^{\circ} \mathrm{C}\right)$ pigs compared to control pigs $\left(22^{\circ} \mathrm{C}\right)$. After 1 and 4-day of cold-stress (b) total plasma IgG was less for cold-stress $\left(8^{\circ} \mathrm{C}\right)$ pigs compared to control pigs $\left(22^{\circ} \mathrm{C}\right)$. Least squares means $\pm \mathrm{SE}$ with a different letter $(\mathrm{a}, \mathrm{b})$ within day differ at $P<0.05$. 


\subsection{Main Effects on Body Weight}

At the start of the study, pig body weight was similar across all treatment groups $(P>0.90)$. Pigs kept at ambient TN temperature tended $(P=0.09)$ to be heavier (28.3 vs. $26.4, \mathrm{SE}=2.2 \mathrm{lbs})$ and gained more $(P=0.004)$ body weight ( $3.2 \mathrm{vs.} 1.3$, $\mathrm{SE}=0.52 \mathrm{lbs})$ compared to COLD-stressed pigs at d-4 post-stress. Neither body weight or body weight gain were affected by floor-space stressors $(P>0.20)$, but body weight gain was greatest among socially INT pigs $(3.2 \pm 0.81 \mathrm{~kg})$ and least among DOM $(0.45 \pm 0.81 \mathrm{~kg})$ pigs at CROWD floor-space $(P=0.01)$.

\subsection{Main Effects on Immune Measures and Cortisol}

There were significant main effects of temperature and social status on lymphocyte proliferation, NK cytotoxicity, prolactin, and cytokines. Lymphocyte proliferation index in response to Con-A was greater $(P<0.05)$ and LPS was less for COLD-stressed pigs compared to pigs at ambient TN temperature (Figure 5). Also, NK cytotoxicity was less among COLD-stressed pigs compared to pigs at ambient TN temperature (49.3 vs. $33.2 \%, \mathrm{SE}=4.3 ; P<0.05)$. Prolactin ( 2.8 vs. $1.9 \mathrm{ng} / \mathrm{mL}, \mathrm{SE}=0.21 ; P<0.05)$ and interferon $(180.9$ vs. $59.4, \mathrm{pg} / \mathrm{mL}, \mathrm{SE}=21.4$; $P=0.03)$ concentrations were less among COLD-stressed pigs compared to pigs at ambient TN temperature and cold-stress had no effect on IL-12 (105.4 vs. 109.0, pg/mL, SE $=46.1 ; P>0.20)$. Moreover, socially INT pigs $(23.1, \mathrm{ng} / \mathrm{mL})$ had less $(P=0.09)$ cortisol than did either DOM or SUB pigs (29.8 and 31.2, SE $=2.1, \mathrm{ng} / \mathrm{mL})$.

Both, ConA- and LPS-induced lymphocyte proliferation indexes were greater $(P<0.05)$ for socially DOM and SUB pigs compared to INT pigs (Figure 6). Socially, DOM $(55 \pm 4.4, \%)$ and INT $(63 \pm 4.1, \%)$ pigs had greater $(P<0.05)$ NK cytotoxicity than did SUB $(43 \pm 3.9, \%)$ pigs. Socially, DOM $(68.2 \pm 8.2, \mathrm{pg} / \mathrm{mL})$ pigs compared to either INT $(24.3 \pm 7.9, \mathrm{ng} / \mathrm{mL})$ or SUB $(20.5 \pm 8.2, \mathrm{pg} / \mathrm{mL})$ had

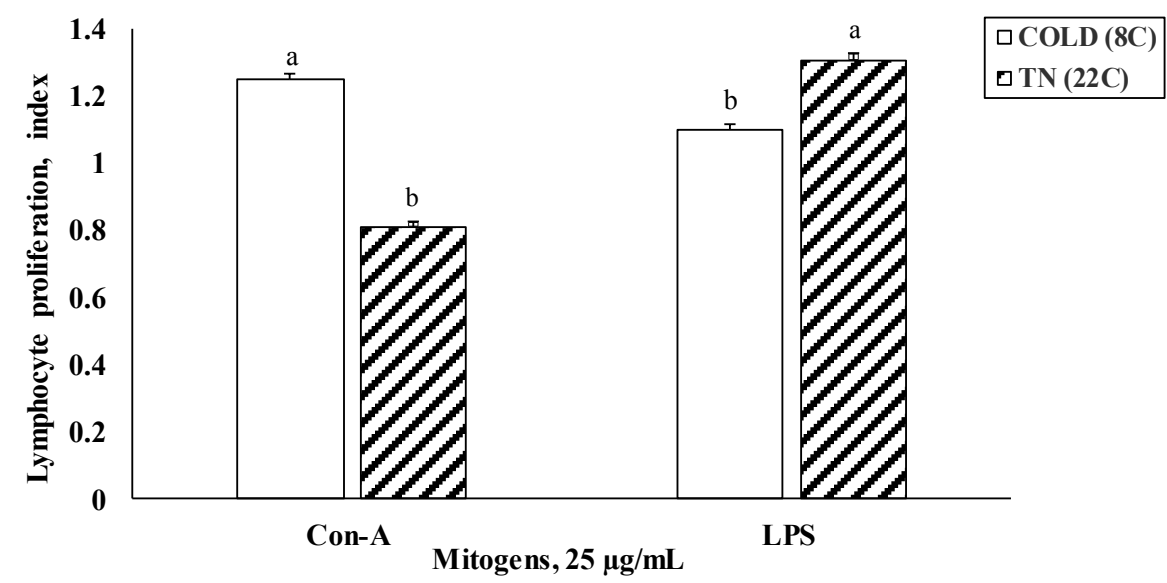

Figure 5. Effect of cold stressor on mitogen-induced lymphocyte proliferation. Socially, dominant and submissive pigs had greater Concanavalin-A (ConA) induced lymphocyte proliferation compared to intermediate pigs. Socially, dominant pigs had greater lipopolysaccharide (LPS) induced lymphocyte proliferation compared to intermediate pigs. Data are expressed as Least square means \pm SE. A different letter $(\mathrm{a}, \mathrm{b})$ differ at $P \leq 0.05$. 


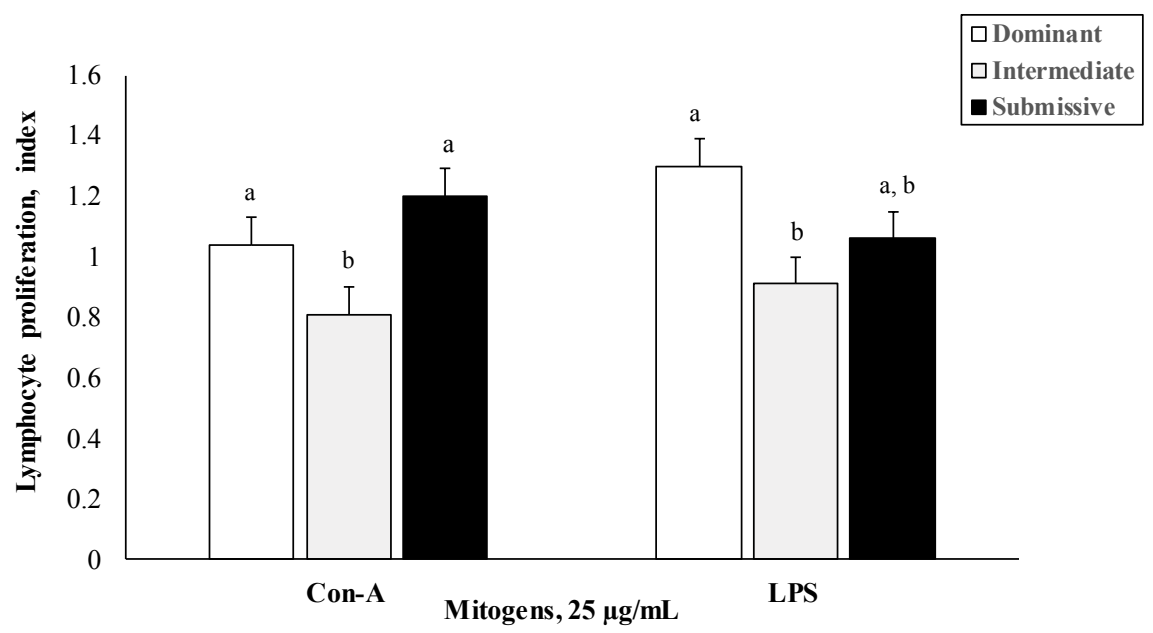

Figure 6. Social status affected mitogen-induced lymphocyte proliferation. Socially, intermediate pigs had lower mitogen-induced proliferation responses to both concanavalin-A (ConA) and lipopolysaccharide (LPS) compared to dominant pigs. Socially, submissive pigs had similar lymphocyte proliferation response as dominant pigs. Least squares means \pm SE with a different letter $(\mathrm{a}, \mathrm{b})$ within mitogens differ at $P<0.05$.

greater $(P=0.05)$ interleukin-10; whereas, INT $(52.8 \pm 9.1, \mathrm{pg} / \mathrm{mL})$ pigs had greater $(P=0.06)$ interferon compared to either DOM $(15.4 \pm 8.9 \mathrm{ng} / \mathrm{mL})$ or SUB $(12.5 \pm 9.2, \mathrm{pg} / \mathrm{mL})$ pigs.

\section{Discussion}

Stress is usually classified depending on type (physical vs. psychological) and duration (acute vs. chronic) of the stressor [15] both which affect the immune responsiveness of an organism. Acute stressors may increase some aspects of the immune systems, and chronic stressors often have detrimental effects [16]. Stress-induced lymphopenia is a typical response to acute stressors [1] [17] but rarely translates to impairment of immune function [18]. In fact, acute heat and shipping stressors [1] [2] [3], as well as chronic heat and crowding stressors [19], have been shown to enhance, suppress, or have no effect on various immune indices. In 6-wk old pigs experiencing acute cold stress ( $\leq 4-\mathrm{h})$, NK cytotoxicity was enhanced [3] and in neonatal pigs total IgG was reduced [20] [21], but TNF- $\alpha$ increased in response to LPS [21]. In 7-wk old pigs, NK cytotoxicity was enhanced in pigs that were experiencing chronic heat, mixing, and crowding stressors [19] and in pigs subjected to chronic cold stress macrophage chemotaxis was reduced [22]. Bacou and colleagues (2017) found that acute social stress-induced leukocyte mobilization including cytotoxic NK cells and T-lymphocytes, but impaired leukocyte function (e.g., cytokine secretion and phagocytic activity) [23]. Still, others have found minimal effects of mixing stress, heat stress, and cold stress on immune function [18].

Interestingly, we found that 4-days of cold stress (chronic) suppressed specific aspects of the immune system including NK, B-cell proliferation, plasma IgG, cytokines, and prolactin, but simultaneously applying crowd stressor did not ex- 
acerbate effects of cold. In fact, crowding stress had no impact on any immune indices measured; thus it is plausible that the crowding stressor partly mitigated the potential adverse effects of cold stress. For example, pigs that were cold and crowded had higher percentages of circulating lymphocytes compared to pigs that were only cold stressed (data not shown). Also, total WBC counts and T-cell proliferation responses were greater among cold-stressed pigs; thus pigs were able to evoke the appropriate immunological response to mitigate the adverse effects of the cold stressor. For example, acute cold stress (4-h) enhanced NK cytotoxicity [3], but chronic cold stress reduced NK cytotoxicity, B-cell, and IgG, but stimulated T-cell proliferation and total WBC counts and alveolar macrophage function [22]. It is possible that specific stressors may disrupt the balance between Th1 and Th2 cells in an attempt to achieve immune homeostasis by interfering directly or indirectly with the immune process [24]. We speculate that is plausible that chronic cold stress may have temporarily skewed the immune response toward a cell-mediated response or a Th1 driven pathway in an attempt to help the animal return to immunological homeostasis [25], not only based on immune indices but the cytokine profile. Cytokines are involved in "driving" the Th1 and Th2 pathways. Despite less INF- $\lambda$ concentrations and similar IL-10 and IL-12 among cold-stressed pigs we still hypothesize that cold stress resulted in an imbalanced immune system. T-cell cytokines are rarely released in the periphery instead are directly transmitted from one cell to another during cell-cell contact [26], thus detecting these cytokines may indicate that the pathways were activated.

The concept that social status is an essential factor in determining the effect of stress on the immune responsiveness of a pig and the biological cost to maintain specific social status in certain circumstances [27] [28] [29] is supported. Establishment of social-dominance rank within a group of pigs previously unfamiliar with one another is accompanied by aggressive fighting [9] [10]. These agonistic encounters between pigs often cause physiological changes, including suppression of the immune system [4] [11]. In the study reported herein, dominance hierarchy was determined in a three-pig model, based on agonistic outcomes among pigs, which resulted in three clearly defined social rankings-dominant (highest), intermediate, and submissive (lowest). The social dynamics of a three-pig model is more complex than that of a two-pig model, which may add to the complexity of interpretation of our findings. Stress effects on the immune system were previously shown to depend on the social status of pigs. Among stressed pigs, dominant pigs display greater NK cell cytotoxicity [1] and higher lymphocyte proliferative response [4] [11] than subordinate pigs. Initial speculation was that immune suppression would most likely occur in lower-ranked animals because it has been shown that there is a biological cost associated with establishing and maintaining social dominance [4] [8] [27].

Surprisingly, pig social status differentially affected the immune responsiveness of pigs to crowd stressor and/or crowd and cold stressors. We found that intermediate pigs (especially when crowded) had enhanced innate immunity 
compared to the dominant pigs. Conversely, among submissive pigs, some immune indices mirrored the dominant pigs (e.g., NK and T-cell proliferation) and others were reflective of intermediate pigs (e.g., phagocytosis and B-cell proliferation). It is plausible that the intermediate pigs benefited the most from the crowd stressor, partly due to reduced agonist encounters between the intermediate and dominant pigs. The intermediate pigs housed at control floor-space allowance gained the least amount of body weight and had reduced innate immunity when compared to their crowded or cold-crowded counterparts. Although less floor-space makes it more challenging to fight, we speculate the reduced floor-space altered the perception of the threat (crowd stressor) of both the intermediate and submissive pigs. Pig social status influenced the homeokinetic response of the pigs to a stressful environment.

Finally, various stressors can affect growth rate and feed-conversion efficiency, which in turn can alter defenses against infectious diseases [30]. In this study, pigs exposed to cold stress for four consecutive days tended to gain less body weight than those pigs at thermoneutral ambient temperature. Exposure to the cold ambient temperature in conjunction with restricted feed intake may have partly contributed to the reduction in body weight since body weight was not affected by the crowd stressor or acute cold stress [4]. Also, in a pilot study, pigs subjected to chronic cold stress and fed ad libitum were not impacted by the stressor which suggest that pigs were able to compensate for the metabolizable-energy diversion required to thermoregulate by increasing voluntary feed intake. Therefore, we conclude that pig body weight and weight gain probably were impacted by the duration of the stressor (chronic nature) and the pigs' inability to mitigate cold stress by increasing feed intake to compensate for body heat loss. Moreover, reduced floor-space did not exacerbate the adverse effects on weight gain due to the cold stressor, perhaps because crowded-pigs could better conserve body energy under limited floor-space conditions. However, dominant pigs that were crowded gained less while gained the most. In this scenario, being dominant may have been advantageous over lower-ranked pigs because these pigs had more readily available bodily reserves and more subcutaneous insulation with which to cope with the cold environment.

\section{Conclusion}

Overall, these findings validate the notion that the impact of stress on the immune response depends not only upon the type and duration of the stressor and the immune indices assessed, but pig social status differentially affects the immunological response evoked. The effects of cold stress on the immune responsiveness of pigs may have been ameliorated by crowd stressor which may partly explain that lack of interactive effects of cold and crowd stressors on immune system. The cold stressor independently enhanced, suppressed, and had no impact on the immune indices measured. Surprisingly, social status differentially affected the immune responsiveness of pigs to the crowd stressor further vali- 
dating the vital role of pig social status on immune responsiveness to specific stressors. Socially, intermediate pigs had enhanced innate immunity, while dominant pigs had enhanced adaptive immunity compared to each other. Pig social rank differentially affected the immune responsiveness to these stressors because they perceived the threat within their environment differently. These data support the concept that both type and duration of the stressor and pig social status influence the kind of immunological response initiated and social status also affects the physiological cost to the animal.

\section{Acknowledgements}

The authors thank Dr. Sandra Rodriguez-Zas for statistical assistance and Drs. John McGlone and Stanley Curtis (deceased) for useful discussion during the course of these studies. This research was supported by a grant funded by the Illinois Agricultural Experiment Station.

\section{References}

[1] McGlone, J.J., Salak, J.L., Lumpkin, E.A., Nicholson, R.I., Gibson, M.L. and Norman, R.L. (1993) Shipping Stress and Social Status Effects on Pig Performance, Plasma Cortisol, Natural Killer Cell Activity, and Leukocyte Numbers. Journal of Animal Science, 71, 888-896. https://doi.org/10.2527/1993.714888x

[2] Morrow-Tesch, J.L., McGlone, J.J. and Salak-Johnson, J.L. (1994) Heat and Social Stress Effects on Pig Immune Measures. Journal of Animal Science, 72, 2599-2609. https://doi.org/10.2527/1994.72102599x

[3] Hicks, T.A, McGlone J.J., Whisnant, C.S., Kattesh, H.G. and Norman, R.L. (1998) Behavioral, Endocrine, Immune, and Performance Measures for Pigs Exposed to Acute Stress. Journal of Animal Science, 76, 474-483. https://doi.org/10.2527/1998.762474x

[4] De Groot, J., Ruis, M.A.W., Scholten, J.W., Koolhaas, J.M. and Boersma, W.J.A. (2001) Long-Term Effects of Social Stress on Antiviral Immunity in Pigs. Physiology \& Behavior, 73, 145-158. https://doi.org/10.1016/S0031-9384(01)00472-3

[5] Kelley, K.W. (1980) Stress and Immune Function: A Bibliographic Review. Annals of Veterinary Research, 11, 445-478.

[6] Kelley, K.W. (1985) Immunological Consequences of Changing Environmental Stimuli. In: Moberg, G.P., Ed., Animal Stress, American Physiological Society, Bethesda, 193-223. https://doi.org/10.1007/978-1-4614-7544-6_12

[7] Moberg, G.P. (2000) Biological Response to Stress: Implications for Animal Welfare. In: Moberg, G.P. and Mench, J.A., Eds., The Biology of Animal Stress: Basic Principles and Implications for Animal Welfare, CABI Publishing, New York, 1-21. https://doi.org/10.1079/9780851993591.0001

[8] Sapolsky, R.M. (2005) The Influence of Social Hierarchy on Primate Health. Science, 308, 648-652. https://doi.org/10.1126/science.1106477

[9] Meese, G.B. and Ewbank, R. (1973) The Establishment and Nature of the Dominance Hierarchy in the Domesticated Pig. Animal Behaviour, 21, 326-334. https://doi.org/10.1016/S0003-3472(73)80074-0

[10] Jensen, P. (1994) Fighting between Unacquainted Pigs: Effects of Age and Individual Reaction Pattern. Applied Animal Behaviour Science, 41, 37-52. https://doi.org/10.1016/0168-1591(94)90050-7 
[11] Tuchscherer, M., Puppe, B., Tuchscherer, A. and Kanitz, E. (1998) Effects of Social Status after Mixing on Immune, Metabolic, and Endocrine Responses in Pigs. Physiology \& Behavior, 64, 353-360. https://doi.org/10.1016/S0031-9384(98)00084-5

[12] Sutherland, M.A., Rodriguez-Zas, S.L., Ellis, M. and Salak-Johnson, J.L. (2005) Breed and Age Affect Baseline Immune Traits, Cortisol and Performance in Growing Pigs. Journal of Animal Science, 83, 2087-2095. https://doi.org/10.2527/2005.8392087x

[13] Lumpkin, E. and McGlone, J.J. (1992) A ${ }^{51} \mathrm{Cr}$ Release Assay for the Determination of Natural Killer Cell Activity. Journal of Nutritional Immunology, 1, 63-74. https://doi.org/10.1300/J053v01n03_08

[14] Miller, A.R.E., Stanisiewski, E.P., Erdman, R.A., Douglass, L.W. and Dahl, G.E. (1999) Effects of Long Daily Photoperiod and Bovine Somatotropin (Trobest ${ }^{\circledR}$ ) on Milk Yield in Cows. Journal of Dairy Science, 82, 1716-1722. https://doi.org/10.3168/jds.S0022-0302(99)75401-9

[15] Koolhaas, J.M., Bartolomucci, A., Buwalda, B., de Boer, S.F., Fluegge, G., et al. (2011) Stress Revisited: A Critical Evaluation of the Stress Concept. Neuroscience \& Biobehavioral Reviews, 35, 1291-1301. https://doi.org/10.1016/j.neubiorev.2011.02.003

[16] Glaser, R. and Kiecolt-Glaser, J.K. (2005) Stress-Induced Immune Dysfunction: Implications for Health. Nature Reviews Immunology, 5, 243-251. https://doi.org/10.1038/nri1571

[17] Stojek, W., Borman, A., Glac, W., Baracz-Jozwik, B., Witek, B., Kamyczek, M., et al. (2006) Stress-Induced Enhancement of Activity of Lymphocyte Lysosomal Enzymes in Pigs of Different Stress-Susceptibility. Journal of Physiology and Pharmacology, 57, 61-72.

[18] Kick, A.R., Tompkins, M.B. and Almond, G.W. (2011) Stress and Immunity in the Pig. CAB Reviews. Perspective in Agriculture, Veterinary Science, and Natural Resources, 6, 51-67. https://doi.org/10.1079/PAVSNNR20116018

[19] Sutherland, M.A., Niekamp, S.R., Rodriguez-Zas, S.L. and Salak-Johnson, J.L. (2006) Impacts of Chronic Stress and Social Status on Various Physiological and Performance Measures in Pigs of Different Breed. Journal of Animal Science, 84, 588-596. https://doi.org/10.2527/2006.843588x

[20] Blecha, F. and Kelley, K.W. (1981) Effects of Cold and Weaning Stressors on the Antibody-Mediated Immune Response of Pigs. Journal of Animal Science, 53, 439-447. https://doi.org/10.2527/jas1981.532439x

[21] Carroll, J.A., Burdick, N.C., Chase, C.C., Coleman, S.W. and Spiers, D.E. (2012) Influence of Environmental Temperature on the Physiological, Endocrine, and Immune Responses in Livestock Exposed to a Provocative Immune Challenge. Domestic Animal Endocrinology, 43, 146-153. https://doi.org/10.1016/j.domaniend.2011.12.008

[22] Salak Johnson, J.L. and Shott, J. (2017) Social Status Impacts Macrophage Function of Pigs. Dairy and Veterinary Science Journal, 2, Article ID: 555590.

[23] Bacou, E., Haurogné, K., Mignot, G., Allard, M., De Beaurepaire, L., et al. (2017) Acute Social Stress-Induced Immunomodulation in Pigs High and Low Responders to ACTH. Physiology \& Behavior, 169, 1-8. https://doi.org/10.1016/j.physbeh.2016.11.012

[24] Kidd, P. (2003) Th1/Th2 Balance: The Hypothesis, Its Limitations, and Implications for Health and Disease. Alternative Medicine Review, 8, 223-246.

[25] Elenkov, I.J. and Chrousos, G.P. (2002) Stress Hormones, Proinflammatory, and 
Antiinflammatory Cytokines and Autoimmunity. Annals of the New York Academy of Sciences, 96, 290-303. https://doi.org/10.1111/j.1749-6632.2002.tb04229.x

[26] Romangnani, S. (2000) T Cell Subsets (Th1 versus Th2). Annals of Allergy, Asthma \& Immunology, 85, 9-18. https://doi.org/10.1016/S1081-1206(10)62426-X

[27] Abbott, D.H., Keverne, E.B., Bercovitch, F.B., Shively, C.A., Mendoza, S.P., et al. (2003) Are Subordinates Always Stressed? A Comparative Analysis of Rank Differences in Cortisol Levels among Primates. Hormones and Behavior, 43, 67-82. https://doi.org/10.1016/S0018-506X(02)00037-5

[28] Goymann, W. and Wingfield, J.C. (2004) Allostatic Load, Social Status and Stress Hormones: The Costs of Social Status Matter. Animal Behaviour, 67, 591-602. https://doi.org/10.1016/j.anbehav.2003.08.007

[29] Lindstom, K.M., Hasselquist, D. and Wikelski, M. (2005) House Sparrows (Passer domesticus) Adjust Their Social Status Position to Their Physiological Costs. Hormones and Behavior, 48, 311-320. https://doi.org/10.1016/j.yhbeh.2005.04.002

[30] Hyun, Y., Ellis, M., Riskowski, G. and Johnson, R.W. (1998) Growth Performance of Pigs Subjected to Multiple Concurrent Environmental Stressors. Journal of Animal Science, 76, 721-727. https://doi.org/10.2527/1998.763721x 